\title{
QUESTÕES POSTAS: (RE)PENSAR BOURDIEU NO CONTEXTO JURÍDICO BRASILEIRO CONTEMPORÂNEO - I
}

\author{
QUESTIONS: (RE)THINKING BOURDIEU IN THE CONTEMPORARY \\ BRAZILIAN LEGAL CONTEXT - I
}

Área: Sociologia Jurídica.

Paulo Victor Fanaia Teixeira ${ }^{1}$

RESUMO: O acúmulo de informações, dados e conhecimento empírico sobre atividades jurídicas pelos profanos, dadas as novas ferramentas de informação e comunicação, e a profusão e maior abrangência do conteúdo jornalístico profissional hoje desafiam os conceitos de campos, habitus, agentes e profanos. Como a teoria de Bourdieu responde às mudanças da contemporaneidade? O presente estudo - que se pretende dividir em três artigos - propõe reflexões teóricas sobre a obra do sociólogo francês e questiona de que modo atores do campo jurídico podem (ou devem) encarar leitores de notícias jurídicas e suas atuações enquanto agentes externos, sobretudo no que tange políticas de comunicação. O estudo aponta para a existência de um público diverso, complexo e merecedor de maior atenção pelos teóricos, indica mudanças paradigmáticas sensíveis na relação destes com os agentes do campo jurídico e enseja questões concretas sobre novas relações sociais. Resta à sociologia o desafio de enquadrá-las e interpretálas. E ao direito?

PALAVRAS-CHAVE: campo jurídico; jornalismo; leitores; profanos; Bourdieu.

\begin{abstract}
The accumulation of information, data and empirical knowledge about legal activities by the profane, given the new information and communication tools, and the profusion and wider scope of professional journalistic content today challenge the concepts of fields, habitus, agents and profane. How does Bourdieu's theory respond to contemporary changes? The present study - which is intended to be divided into three articles proposes theoretical reflections on the work of the French sociologist and asks how actors in the legal field can (or should) face legal news readers and their actions as external agents, especially in what regarding communication policies. The study points to the existence of a diverse,
\end{abstract}

\footnotetext{
1 Bacharel em Jornalismo (2013) pela Universidade Federal de Ouro Preto (UFOP); Mestre em Sociologia pela Faculdade de Letras da Universidade do Porto (FLUP-UP); Ex-editor e Ex-repórter de Olhar Jurídico (2016-2019). paulovictorfanaia@gmail.com
} 
complex and deserving of greater attention by theorists, indicates sensitive paradigmatic changes in their relationship with agents in the legal field and raises concrete questions about new social relationships. Sociology faces the challenge of framing and interpreting them. What about the law?

KEYWORDS: legal field; journalism; readers; profane; Bourdieu.

SUMÁRIO: Introdução. 1. O Pensamento de Bourdieu - elementos chave. 2. Pensando o jurídico. 3. Da linguagem jurídica. 4. Visão científica - visão vulgar. 5. Diferenciação e ausência. Conclusão. Referências bibliográficas.

\section{Introdução}

Estruturalista, filho do cientificismo de Émile Durkheim (1858-1917) e do objetivismo de Karl Marx (1818-1883), Pierre Bourdieu (1930-2002) tinha na análise estrutural o pilar de seu estudo sobre os fatos sociais. A perspectiva relacional de Max Weber (1864-1920) e os estudos de Marcel Mauss (18721950) sobre o corpo, entretanto, conferiu à sua abordagem caráter distintivo e multifacetado, pois, embora trabalhasse com análises a partir de estruturas objetivas, não as concebia enquanto realidades estáticas. Para ele, "os agentes sociais e as relações de força que estes estabelecem entre si condicionam e são condicionadas pelas estruturas que orientam a vida social" (COELHO, KOZICKI \& ALMEIDA, 2013, p.71). Noção que se traduziria na necessidade de forjar um novo sistema de pensamento, o que lhe exigiria recorrer a referências diversas - inclusive a Aristóteles ${ }^{2}$. A empreitada resulta em um modelo de análise que identifica e descreve com considerável êxito a estrutura de um campo, a disposição dos capitais, a posição dos agentes, além da adoção de linguagem, vestuário, gestual e uma série de outros indicadores específicos dos campos, sem abandonar a noção de estrutura - pelo contrário, percebendo-os enquanto elementos estruturantes. Sua obra marca o século XX. Indiscutivelmente rigoroso em termos metodológicos, Bourdieu não se furtava de acumular, analisar, interpretar e utilizar dados quantitativos e qualitativos em suas análises. Destacava seu "forte apego à pesquisa de campo, exigência central" de sua sociologia (BARROS, 2010). Competitivo, fundou sua própria revista acadêmica, Actes de la recherche en sciences sociales, rivalizou com modelos distintos de pensamento e controlou minusiosamente publicações de sua co-autoria

\footnotetext{
2 Conceito de doxa
} 
(CATANI, NOGUEIRA, HEY \& MEDEIROS, 2017), tanto em conteúdo quanto na forma - ora redigindo artigos com impiedosa linguagem hermética aos seus pares, ora adaptando textos de intervenção política para linguagem apropriada aos populares.

Do ponto de vista das mudanças sociais, pesava em seus textos certo descrédito à noção marxista de "resistência" através da "conscientização" das opressões (dedução que considerava superestimada). Esta visão, associada ao pensamento de uma sociedade estruturada e caracterizada por mecanismos mais voltados à resistência do que à mudança, lhe rendeu fama de "pensador das permanências" - preconceito a que Bourdieu tomou ciência, rebatendo ao que chamava de "autoconfiança dos intelectuais, sobretudo os de esquerda". Dizia: "Sou visto como pessimista, como alguém que desestimula as pessoas etc. Mas considero que é melhor saber a verdade" (ZIZEK, 2013, p.268)3. A verdade - supunha - era que "levar à consciência os mecanismos que tornam a vida dolorosa, inviável até, não é neutralizá-los; explicar as contradições não é resolvê-las" (CATANI, NOGUEIRA, HEY \& MEDEIROS, 2017, p.45).

Uma leitura pormenorizada de sua obra sugere, entretanto, não se tratar de "pessimismo". O autor buscava revelar as diferenças materiais entre os indivíduos e os mais profundos, imperceptíveis e até inconscientes modelos de reprodução do status quo. Bourdieu interpretou o "jogo de poder das distinções econômicas e culturais de uma sociedade hierarquizada" ao identificar "os condicionamentos materiais e simbólicos [que] agem sobre nós (sociedade e indivíduos), numa complexa relação de interdependência" (SETTON, 2010, 14 de março). Doravante, como não faltam condicionamentos, pouco restava de fôlego para uma leitura habermasiana da realidade social. Nem havia essa intenção. A sociologia - supunha o francês - é atividade desencantadora do mundo (expressão de Weber levada à cabo em sua carreira) e desnaturalizante das práticas sociais, pois revela o vazio das idealizações (que não germinam no solo do social) e expõe o quão socialmente explicáveis são os atos e discursos que cremos "evidentes", "íntimos" ou "naturais" (inspiração durkheimiana). Na teoria bourdieusiana, não há espaços para conclusões voltadas a projetos emancipadores. Ocupa-se de revelar a realidade social tal como ela é e não como deveria ser. Da mesma forma, tratou o ser humano tal como o conheceu, em toda sua baixeza, seja em sua traumatizante experiência acadêmica em Paris - dado o seu mal encaixe ao habitus acadêmico-metropolitano de seus colegas, muito disso atribuído às suas

\footnotetext{
Manifestação feita na ocasião do debate com o colega inglês Terry Eagleton.
} 
origens (os Pirenéus, sudoeste da França), o que lhe rendeu impopularidade e aversão aos renomados concorrentes da época, sobretudo Jean Paul Sartre - seja seu frustrante, porém, instigante, serviço militar na Argélia - onde encarou a face mais perversa do neocolonialismo europeu, o que resultou em sua primeira obra "Sociologie de L'Algérie" (1958).

Fato é que sua biografia revela muito de seu pensamento, mas muito pouco de seus afetos - encarado, por quem desfrutou de sua convivência, como alguém ranzinza e de difícil trato - o mais próximo que chegou de uma reflexão íntima sobre sua trajetória (a qual, por sinal, mérito algum atribuía, senão às condições sociais que a explicavam) encontra-se em "Esboço para uma autoanálise"4 (2001), - quando de fato se inseriu na obra ao "assumir o ponto de vista do autor" (CATANI, 2008, p.63) - sua última obra.

Bourdieu falece em 2002, deixando extensa bibliografia, revista acadêmica e um sistema de pensamento ainda hoje aplicado nas academias europeias e no Brasil, principalmente nas Ciências Sociais e nas Comunicações. Dedicou a vida à aplicação de seu modelo, nos mais diversos campos.

Teorizou, contudo, muito pouco sobre as experiências tecnológicas, as quais se submeteu, sobretudo no fim da vida - embora já tivesse, em 1999, detectado as alterações impostas ao universo político pelo jornalismo televisivo ${ }^{5}$. Nos seus últimos anos, chegou a promover videoconferências, trocar e-mails com colegas e co-autores e ser alvo de produções audiovisuais - menos do que poderia, mas certamente mais do que gostaria.

O fato é que, dezoito anos após seu falecimento, muita coisa mudou em termos de tecnologias da informação e da comunicação. A internet tem revolucionado incontáveis aspectos da vida cotidiana, sobretudo as relações sociais, tornando-as mais complexas e dinâmicas, para dizer o mínimo. Derrubamse barreiras, a noção de espaço-tempo ganha novos sentidos e as relações de trabalho ocupam o terreno do virtual (ou vice-versa), a contemporaneidade insere novos agentes sociais nos campos que a teoria bourdieusiana desenhou. Aparelhos celulares, tablets e redes sociais consolidam-se como indispensáveis ferramentas de trabalho e, em 2020, no contexto da pandemia do novo coronavírus (Covid-19), as videoconferências com participantes diversos, as lives e o home office sugerem novos paradigmas às Relações Humanas $(\mathrm{RH})$ e põem em causa a necessidade do encontro físico no contexto do trabalho intelectual.

\footnotetext{
4 No Brasil, "Esboço de auto-análise", publicado em 2005 pela Companhia das Letras.

5 “A sociologia do campo político", conferência que abordaremos adiante.
} 
Novos atores sociais, novas profissões, novas ferramentas de trabalho e novos modelos de comunicação. Como a teoria do campo jurídico absorve estes impactos? No que ela pode nos ajudar a interpretar o que temos? Quais rearranjos seriam necessários para não perder, no horizonte teórico, o avanço das mudanças sociais da contemporaneidade?

Esta série de artigos pretende, não responder, mas reformular questões sociológicas ao espaço jurídico brasileiro, a partir do pensamento de Bourdieu. Do ponto de vista teórico, debate a pertinência e adaptabilidade da teoria no contexto das dinâmicas sociais contemporâneas. O objetivo geral do estudo é introduzir atores sociais, cuja pertinência, caracterização e ação - acredita-se - os tornem consideráveis nos futuros estudos sobre o jurídico brasileiro. Neste sentido, têmse que o debate não se centra em questões de ordem técnica ou da norma jurídica, especificamente, mas nas relações sociais no campo jurídico. Dentre os objetivos específicos, temos: reelaborar questões sobre a teoria bourdieusiana no contexto jurídico brasileiro contemporâneo e fornecer questões relativas as relações sociais que o Poder Judiciário estabelece com a sociedade hoje, sobretudo em termos de política comunicacional.

\section{O Pensamento de Bourdieu - elementos chave}

Antes de iniciarmos propriamente no pensamento do autor, convêm estabelecer algumas premissas: o direito - no sentido sociológico mais vasto - "é uma ordem edificada pelo homem, por convenção ou deliberação, em função da diferenciação espontânea das relações sociais no interior de uma comunidade concreta", o que pressupõe poder e submissão pelos membros do grupo, ou seja, alguma "dimensão política". Portanto, "no jurídico está necessariamente implicado o político" (PINA, 2009, p.28). Em outras palavras, a "política faz o direito" e "as mudanças sociais o condicionam. Assim, a forma jurídica constituise como... manifestação concreta da organização dos homens, na história" (ARRUDA JR, 1993, p.15). Em Durkheim, temos que a "regularidade da vida social depende da existência de normas que não só constituem o modo coletivo de agir e conceber o mundo mas exercem ainda uma coerção externa" sobre os indivíduos (PINA, 2009, p.29).

A arquitetura do pensamento bourdieusiano - se quisermos ao longo destes artigos nos aproximar do autor - exige fundamentalmente que invoquemos algumas categorias estruturantes da análise, tais como domínios de saber e 
linguagem, relação dominantes - dominados, autorizações e consagrações de agentes e relações de poder, que se valem de conceitos como: campo, homologia, habitus e violência simbólica. O primeiro, que nos será de maior importância, podemos definir já como um microcosmo, "espaço" ou "sistema" abstrato, porém, estruturado, incluído no macrocosmo do espaço social, relativamente autônomo e dotado de agentes submetidos a uma lógica própria, além de leis e regras específicas, contudo, que disputam - através das práticas e estratégias de conservação e subversão - posições de poder (CATANI, NOGUEIRA, HEY \& MEDEIROS, 2017). Um campo é fundamentalmente marcado por luta e resistência. "Essas posições são obtidas pela disputa de capitais específicos, valorizados de acordo com as características de cada campo. Os capitais são possuídos em maior ou menor grau pelos agentes que compõem os campos, diferenças essas responsáveis pelas posições hierárquicas que tais agentes ocupam" (PEREIRA, 2015, p.341).

Bourdieu não apenas caracteriza a estrutura do campo - seja jurídico ou outro - mas descreve seu funcionamento e as lógicas subjacentes aos processos, sobretudo a partir da análise das posições e das relações dos agentes, percebendo os mecanismos de dominação, resistência, conservação (sobre os "recémchegados" ou profanos, por exemplo) e subversão do campo, que resultam em disputas internas pelo controle e legitimação dos bens e da regulação, imposição e, eventualmente, contestação das normas. Neste complexo sistema de disposições, sociologicamente definíveis e "socialmente constituídas", Bourdieu (2007) denominará habitus - entendido como "sistema de disposições socialmente constituídas que, enquanto estruturas estruturadas e estruturantes, constituem o princípio gerador e unificador do conjunto das práticas e das ideologias características de um grupo de agentes" (p. 191).

Os que participam da luta contribuem para a reprodução do jogo contribuindo $[. .$.$] para produzir a crença no valor do que está$ sendo disputado. Os recém-chegados devem pagar um direito de entrada que consiste no reconhecimento do valor do jogo [...] e no conhecimento (prática) dos princípios de funcionamento do jogo. Eles são levados a estratégias de subversão que, no entanto, sob pena de exclusão, permanecem dentro de certos limites. E de fato, as revoluções parciais que ocorrem continuamente nos campos não colocam em questão os próprios fundamentos do jogo (BOURDIEU, 
1983, p.91 apud PEREIRA, 2015, p.349).

\section{Pensando o jurídico}

Percebe Bourdieu (2011), já nos aproximando ao campo jurídico, que questões como a "necessidade jurídica" (trabalho de construção social da realidade que permite a tradução de uma injustiça em um agravo juridicamente percebido, nomeado e imputado), a capacidade de condução de uma questão jurídica, as tradições, as regras, exigências de validação e consolidação do rito jurídico, formalidades, liturgia, linguagem e a própria estrutura de texto adotada pelos agentes jurídicos são estruturados e estruturantes de uma relação caracterizada pela dominação e que, a grosso modo, tende a definir-se pela noção de abertura e fechamento de "fronteiras" - tanto em relação às posições internas dos agentes quanto às dos agentes em relação aos que não compõem o campo.

A constituição do campo jurídico condiciona o monopólio do "direito de dizer o direito" (BOURDIEU, 2011, p.220). De fato, como elabora Carlomagno (2011), o campo jurídico institui o monopólio do acesso ao direito, de modo que apenas seus profissionais habilitados - "os únicos capazes de adotar postura correta perante a lei” (p.246) - nele atuem. Essa imposição de fronteiras implicaria, ainda conforme Carlomagno (2011, p.246), na "retirada de posse e de direitos do cidadão" na medida em que este, desautorizado a agir juridicamente e incapaz de compreender a linguagem jurídica, se vê obrigado a recorrer aos profissionais quando necessária uma ação jurídica.

$\mathrm{O}$ efeito de hermetismo (l'effet de fermeture) que o próprio funcionamento do campo tende a exercer manifesta-se no facto de as instituições judiciais tenderem a produzir verdadeiras tradições específicas e, em particular, categorias de perceção e de apreciação perfeitamente irredutíveis às do não-especialistas, gerando os seus problemas e as suas soluções segundo uma lógica totalmente hermética e inacessível aos profanos (BOURDIEU, 2011, p.243).

Ora, percebe Bourdieu (2011), este efeito obtido não apenas resulta da definição dos conflitos a se tornarem jurídicos, como a própria forma pela qual se devem revesti-lo, de modo a reconhecer-se como debate jurídico, através de recursos e mecanismos que reduzem "a realidade à sua definição jurídica, essa ficção eficaz" (p.243). Para o autor, a linguagem é um principais aspectos 
definidores e distintivos de campo (além de vestuário, gestos e ritos, que também são alvos de análise).

\section{Da linguagem jurídica}

A linguagem jurídica, conforme Bourdieu, seria autônoma e constituída por lógica própria e específica de funcionamento, "linguagem altamente restrita e codificada" (NETO \& MEZZAROBA, 2016, p.127):

Por meio da linguagem oficial e oficiosa, extensiva a gestos, vestuário, relações sociais, formalidades e outros elementos, cristalizam-se os espaços privilegiados do poder jurídico e ocorre o mascaramento do caráter arbitrário das significações da dominação que interiorizam nas pessoas os elementos capazes de estruturar o ethos jurídico (MICELI, 1987, LIII. In: TAVARES NETO \& MEZZAROBA, 2016, p.128).

A transmutação da linguagem vulgar para a linguagem jurídica resultaria em dois efeitos identificados por Bourdieu: a "neutralização", "próprias para marcar a impessoalidade do enunciado normativo e para constituir o enunciador em sujeito universal, ao mesmo tempo impessoal e objetivo" (BOURDIEU, 2011, p.224); e a "universalização", através do recurso ao indicativo ao citar normas jurídicas, emprego de verbos na terceira pessoa do singular (presente e passado, "aceita"; "confessa"; "compromete-se"), bem como o uso de indefinidos ("todo o condenado") e do presente intemporal, de modo a exprimir generalidade e omnitemporalidade; emprego de valores trans-subjetivos (que suporia consenso ético) em expressões como "como toda boa mãe" ou "bom pai de família" (BOURDIEU, 2011). Todos estes recursos, com formas fixas e inflexíveis, resultam em um texto jurídico neutro, universal, sólido e bem estruturado, concedendo pouco espaço para manifestações de individualidade por parte dos agentes.

Esta retórica da autonomia, da neutralidade e da universalidade, que pode ser o princípio de uma autonomia real dos pensamentos e das práticas, está longe de ser uma simples máscara ideológica. Ela é a própria expressão de todo o funcionamento do campo jurídico e, em 
especial, do trabalho de racionalização, no duplo sentido de Freud e Weber, a que o sistema de normas jurídicas está continuamente sujeito, e isto desde há séculos. Com efeito, aquilo que se chama "o espírito jurídico" ou "o sentido jurídico" e que constitui o verdadeiro direito de entrada no campo (evidentemente, com uma mestria mínima dos meios jurídicos acumulados pelas sucessivas gerações, quer dizer, do corpus de textos canónicos e do modo de pensamento, de expressão e de acção em que ele se reproduz e que o reproduz) consiste precisamente nesta postura universalizante. Esta pretensão estatutária a uma forma específica de juízo, irredutível às intuições frequentemente inconstantes do sentido da equidade, pois que se baseia na dedução consequente a partir de um corpo de regras sustentado pela sua coerência interna, é um dos fundamentos da cumplicidade, geradora de convergência e de comutatividade, que une, na concorrência pelas coisas em jogo e por meio dessa concorrência, o conjunto, todavia muito diferenciado dos agentes que vivem da produção e da venda de bens de serviços jurídicos (BOURDIEU, 2011, pp.225-226).

Conforme o sociólogo (2011), o ato da interpretação do texto jurídico, diferentemente dos textos do campo da filosofia e da literatura (uma vez que se orienta para fins práticos, não tendo nele próprio sua finalidade) limita divergências entre os intérpretes autorizados, o que anula a coexistência de normas jurídicas concorrentes. Um sistema regulado de instâncias hierarquizadas impede, na prática, que juristas - ainda que opostos em suas interpretações da norma - a

extrapole, garantindo sempre um acordo entre intérpretes e interpretações. É precisamente da limitada divergência de interpretação do texto jurídico que resulta a impressão do funcionamento do corpo jurídico como "aparelho" coeso, eficiente, hierarquizado e, para os leigos, quase automático e codificado.

\section{Visão científica - visão vulgar}

Da absorção e reprodução deste conjunto de normas e procedimentos derivam os desvios entre agentes autorizados e não autorizados, análises de especialistas e de não- especialistas, visão científica e visão vulgar etc. Ora, essa iniquidade entre posse e desposse - percebe Bourdieu (2011, p. 235) nada tem de acidental, é precisamente a constituição desta relação de poder. 
Relação marcada - sobretudo por constantes procedimentos bem-sucedidos de conservação da ordem e do monopólio profissional especializado - tanto em relação ao alargamento do mercado, no surgimento de profissionais jurídicos semiespecializados e do autoconsumo jurídico em empresas privadas, quanto eventuais figuras não-profissionais e coletivos que possam despontar no debate jurídico. Exemplifica:

Dentro da mesma lógica, já se pôde mostrar que a vulgarização militante do direito do trabalho, que assegura a um número importante de não-profissionais um bom conhecimento das regras e dos procedimentos jurídicos, não produz o efeito de garantir uma reapropriação do direito pelos utilizadores em detrimento do monopólio dos profissionais, nem tão-pouco o efeito de determinar uma deslocação da fronteira entre os profanos e os profissionais os quais, impelidos pela lógica da concorrência no seio do campo, têm de aumentar em cientificidade para conservarem o monopólio da interpretação legítima e escaparem à uma desvalorização associada a uma disciplina que ocupa uma posição inferior no campo jurídico (BOURDIEU, 2011, p.246)

Bourdieu (2011) identifica ainda a cumplicidade estabelecida pela proximidade de interesses e de afinidade de habitus entre dominantes do campo jurídico para/com dominantes dos demais campos, como espécie de pacto de não-agressão - tanto mais eficaz quanto mais inconsciente e sutil. A relação de dominação no campo jurídico revela-se efetiva "na medida em que permanece desconhecida (méconnue) a parte maior ou menor de arbitrário que está na origem do seu funcionamento" (BOURDIEU, 2011, p.255).

A "neutralidade" e a "autonomia do direito e seus agentes" (Bourdieu, 2011) impõe-se como fundamento da ideologia do profissional jurídico. Ainda, às práticas jurídicas, recairia a "universalização prática" (p.257) e o "efeito normalizador" (p.258), resultantes da sistematização e da racionalização de um modo específico de agir e expressar-interpretados como mecanismo de dominação simbólica e de imposição da legitimidade de uma ordem social. Com aparente fundamento na realidade, o direito impõe universalmente "uma representação da normalidade em relação à qual todas as práticas diferentes tendem a aparecer como desviantes, anósmicas, e até mesmo anormais, patológicas" (p.259). 
Elabora:

Os poderes da homologação só são exercidos plenamente por aqueles que estão ao mesmo nível no universo regulado do formalismo jurídico: as lutas altamente racionalizadas que ela consente estão reservadas, de facto, aos detentores de uma forte competência jurídica, à qual está associada - sobretudo entre os advogados - uma competência específica de profissionais da luta jurídica, exercitados na utilização das formas e das fórmulas como armas. Quanto aos outros, estão condenados a suportar a força da forma, quer dizer, a violência simbólica que conseguem exercer aqueles que - graças à sua arte de pôr em forma e de pôr formas - sabem, como se diz, pôr o direito do seu lado e, dado o caso, pôr o mais completo rigor formal, sumтum jus, ao serviço dos fins menos irrepreensíveis, summa injuria (BOURDIEU, 2011, p.263).

\section{Diferenciação e ausência}

Ora, do ponto de vista teórico, podemos perceber que Bourdieu constrói seu modelo de análise a partir da diferenciação. Isto é, define o agente de um campo pelo que ele é e, portanto, pelo que não é, delimitando, assim, o que transforma o indivíduo "neste" e não "naquele" agente do campo e, partindo destas diferenças, identifica as relações que "este" e "aquele" estabelecem entre si e com os outros, as posições que ocupam e que disputam etc. Há em cada agente, portanto, uma série de elementos sociologicamente detetáveis para caracterizá-lo enquanto tal - sendo eles, todavia, percetíveis somente se analisados em relação aos demais agentes, de modo interdependente ${ }^{6}$.

Neste sistema de pensamento, a figura do profano surge caracterizado pela ausência. Isto é, esculpe-se uma noção relativamente abstrata do que ele representa por aquilo que ele não é em relação a determinado campo. Logo, identifica-se o profano pelas competências que ele não domina, pela linguagem que não utiliza, pelo que não faz e não representa em relação a um campo. A esse conjunto de "ausências" de domínios específicos, Bourdieu denominará

\footnotetext{
6 Sobre isso, bem elabora Clóvis de Barros Filho, a pretexto de exposição sobre o pensamento de Bourdieu: só se define um chefe na medida em que define seus empregados. Sem empregados, não há chefe e, portanto, impossível seria defini-lo enquanto tal.
} 
"desposse". Desapossado, por tanto, é o indivíduo que não possui as competências e as credenciais exigidas para agir e jogar o jogo de determinado campo. Define-se ainda pela ação inconsciente de interiorizar, suportar e reproduzir os mecanismos de dominação o qual está sujeito ${ }^{7}$.

Portanto, temos que a noção de campo situa-se na separação entre os profissionais e profanos (CASTRO, 2017). Como pressuposto tácito do acordo, estes devem ser excluídos do jogo, uma vez que não correspondem aos critérios de acesso e não reproduzem as condições sociais e simbólicas impostas.

A entrada no "espaço jurídico" supõe a "conversão de todo o espaço mental" e, particularmente - de "toda a postura linguística" - que de entrada se exige. Nesse sentido, a competência jurídica escapa às recomendações do senso comum, o que implica em desqualificar a noção de equidade dos não-especialistas e revogar sua visão do fatos, isto é, a visão vulgar sobre um fato de interesse jurídico (BOURDIEU, 2011). Ora, a cisão entre a visão vulgar e a visão científica do direito nada tem de acidental, pelo contrário, é a própria constituição desta relação de poder. Esse desvio entre profissionais e profanos - fundamento de um desapossamento - resulta do fato de que, através da estrutura e do sistema de princípios de visão e divisão do campo jurídico, impõe-se "um sistema de exigências cujo coração é a adoção de uma postura global, visível, sobretudo, em matéria de linguagem" (BOURDIEU, 2011, p.236). Não obstante:

A concorrência pelo monopólio do acesso aos meios jurídicos herdados do passado contribui para fundamentar a cisão social entre os profanos e os profissionais favorecendo um trabalho contínuo de racionalização próprio para aumentar cada vez mais o desvio entre os veredictos armados do direito e as intuições ingénuas da equidade e para fazer com que o sistema das normas jurídicas apareça aos que a ele estão sujeitos, como totalmente independente das relações de força que ele sanciona e consagra (BOURDIEU, 2011, p.221).

Embora o conceito de campo jurídico sugira solidez e certa inflexibilidade no que tange seu rigor, estrutura, fronteiras e critérios de entrada, a teoria bourdieusiana, propriamente dita, revela alguma flexibilidade, sugerindo

\footnotetext{
7 Concepção, cuja abjeção de seu colega Terry Eagleton, percebe-se em evento realizado pelos autores na ocasião da visita daquele ao Instituto de Artes Contemporâneas de Londres, a 15 de maio de 1991. (ZIZEK, [1994] 2013).
} 
alterações e novos enquadramentos - evidentemente, na medida em que dados empíricos os comprovam. Em "A sociologia do campo político", Bourdieu (1999 apud CASTRO, 2017), reconhece, por exemplo, a inclusão de novos agentes naquele campo, como resultado das transformações ocorridas nos últimos vinte $\operatorname{anos}^{8}$. Refere- se aos jornalistas (sobretudo os de televisão) e especialistas em pesquisa de opinião - agentes que antes se caracterizavam como espectadores do campo político e que se tornaram "agentes em primeira pessoa", em razão de produzirem efeitos sobre o campo. Para descrever o campo político hoje conclui Bourdieu - é preciso incluir essas categorias de agentes.

$\mathrm{O}$ autor explica o que o faz reconhecer determinado indivíduo ou instituição como agente do campo. "[...] é simples: reconhece-se a presença ou existência de um agente em um campo pelo fato de que ele transforma o estado do campo (ou que, se o retirarmos, as coisas se modificam significativamente)" (CASTRO, 2017, p.107).

Hoje, vinte e um anos após "A sociologia do campo político", como identificar e enquadrar a profusão de jornalistas e especialistas em pesquisa de opinião no campo político? Como as novas tecnologias de informação e comunicação (que resultam em novos modelos de produção de informação e conteúdo jornalístico profissional e amador, como blogs, vídeos e canais em sites de stream) e o aumento da velocidade com que conteúdos jornalísticos atingem seu público afetam o estado do campo e a própria teoria?

Ainda para explicar a relação estabelecida entre agentes e profanos, Bourdieu invoca Weber e seu conceito de "monopólio da manipulação legítima dos bens de salvação", concebido para se referir à reação clerical e à intenção feminina de oficiar missa ou dar extrema-unção - durante a reforma protestante - atos que denunciavam como exercício ilegal da profissão. Na esteira deste raciocínio, elabora Bourdieu que quanto mais o campo político se constitui, autonomiza e profissionaliza, mais seus agentes tendem a encarar profanos com comiseração, reivindicando à ordem, caso estes, irresponsavelmente, apresentemse como intrusos à política (CASTRO, 2017). O absurdo do ato se daria pela revelação de um pressuposto tácito, qual seja, de que da política estão excluídos os profanos e, portanto, caberia apenas aos políticos falarem de política com a competência (técnica e jurídica) necessária.

O campo jurídico, parece evidente, possui fronteiras e critérios de acesso ainda mais claros que o campo político e religioso. Todo jovem advogado e,

$8 \quad$ Entre os anos de 1979 e 1999. 
certamente, seus familiares próximos sabem o que significa submeter-se e lograr êxito em um exame da Ordem dos Advogados do Brasil (OAB). Do mesmo modo, o "exercício ilegal do direito" parece-nos mais grave que o "exercício ilegal da política" ou das atividades religiosas. Como vimos neste artigo, há, no campo jurídico, uma imposição clara e bem-sucedida de critérios e procedimentos de entrada e mecanismos sistemáticos de controle sobre os agentes. $\mathrm{O}$ que faz tender o campo jurídico a um fechamento ainda maior em relação aos profanos. Nos campos político e religioso, temos que, ainda que haja alguma tendência à restrição, estes permanecem submetidos ao veredito dos leigos (CASTRO, 2017, p.106), por motivos óbvios: não há padre sem fiéis, nem político sem eleitores. Já no campo jurídico, dada a natureza não-eletiva dos cargos do Poder Judiciário, o mesmo não se percebe. Somado a isto, temos que os agentes, dados os fatores elencados pelo estudo, gozam de um agir relativamente (porém, nunca absolutamente) autônomo e de um distanciamento simbólico ainda maior em relação aos profanos.

\section{Conclusão}

O legado de Bourdieu justifica o quanto sua teoria fora explorada academicamente ao longo dos anos para perceber e descrever os campos sociais - incluindo o do jornalismo e o das artes. Enquanto a vida permitiu, o sociólogo dedicou-se a comprovar as aplicabilidades de seu modelo aos campos que considerava melhor estruturados e, portanto, de exercício intelectual frutífero o que o fez com inquestionável sucesso. Contudo, muita coisa ficou para trás. Seu modelo - percebe Lahihe (2006 apud CATANI, NOGUEIRA, HEY \& MEDEIROS, 2017, p.66):

[...] permaneceu insensível em relação a outras diferenças que são também cruciais e podem levar a designar, de outro modo, determinados "campos": o grau de profissionalização do campo e, em particular, de estabilização dos atores no campo; a relação entre os agentes do campo e o 'público' ao qual eles dirigem ou a quem eles destinam suas produções (obras, discursos, competências, etc.); o grau de esoterismo ou exotismo com o qual os agentes do campo podem praticar sua atividade, etc. 
Tais análises revelam-se pertinentes em maior ou menor grau, conforme o campo estudado, sendo mais recorrentes ao tratarem dos campos da comunicação social (por conta dos novos formatos e agentes produtores de informações) e das artes (com o advento das novas correntes artísticas, coletivas ou individuais, que de certa maneira rompem com a noção de autor, peça central da análise bourdieusiana). Evidente que, diferentemente destes, o campo jurídico revela-se mais estruturado e, portanto, mais conservado e resistente às mudanças sociais, razão que explica a obra de Bourdieu permanecer adequada para compreendê-lo. Todavia, é razoável e salutar considerar que alguns aspectos tenham mudado ao longo dos últimos anos. Interessa ao estudo identificar a relação e o modelo de comunicação estabelecido entre os agentes do campo jurídico e os profanos como um destes, o que faremos na continuação deste artigo.

\section{Referências bibliográficas}

ARRUDA JR., Edmundo Lima. Introdução à sociologia jurídica alternativa. São Paulo: Ed. Acadêmica, 1993

BARROS FILHO, Clóvis de. A sociologia de Bourdieu desmascara os interesses na produção da notícia, mas também suas críticas acadêmicas mais ingênuas. 2010. Revista Cult (Online). https://revistacult.uol.com.br/home/a-dinamica-dosmeios-de- comunicacao/ Acesso em: 03/08/2020

BOURDIEU, Pierre. A economia das trocas simbólicas. $5^{\text {a }}$ Ed. São Paulo: Perspectiva, 2007

. O Poder Simbólico. 2a Ed. Lisboa: Edições 70, 2011.

CARLOMAGNO, Márcio Cunha. Constituindo realidades: sobre A força do direito de Pierre Bourdieu. Sociologia, Revista da Faculdade de Letras da Universidade do Porto, V. 22, p. 245-249, 2011

CATANI, Afrânio Mendes. Pierre Bourdieu e seu esboço de auto-análise. Eccos Revista Científica, São Paulo, v.10, p.45-65, dez. 2008

CATANI, Afrânio Mendes; NOGUEIRA, Maria Alice; HEY, Ana Paula; 
MEDEIROS, Cristina Carta Cardoso de (Orgs.). Vocabulário Bourdieu. $1^{\text {a }}$ Ed. Belo Horizonte: Autêntica Editora, 2017

CASTRO, Celso. Textos básicos de sociologia. De Karl Marx a Zygmunt Bauman. $2^{\text {a }}$ Ed. Rio de Janeiro: Zahar, 2017

COELHO, Sérgio Reis; KOZICK, Katya; ALMEIDA, Paula Josiane. Apontamentos sobre o método empregado por Pierre Bourdieu nas ciências sociais e a sua repercussão no âmbito jurídico. Revista de Direitos Fundamentais e Democracia, Curitiba, v. 13, n. 13, p. 64-80, jan./jun., 2013

PEREIRA, Elaine Aparecida Teixeira. O conceito de campo de Pierre Bourdieu: possibilidade de análise para pesquisas em história da educação brasileira. Revista Linhas. Florianópolis, v. 16, n. 32, p. 337 - 356, set./dez. 2015

PINA, Sara. Media e leis penais. Coimbra: Almediva, 2009

NETO, José Querino Tavares; MEZZAROBA, Orides. O método enquanto pressuposto de pesquisa para o direito: a contribuição de Pierre Bourdieu. Revista de Direito Brasileira, Florianópolis, V.15, n.6 p.116-132, set/dez, 2016 doi:http://dx.doi.org/10.26668/IndexLawJournals/2358-1352/2016.v15i6.3036

SETTON, Maria da Graça Jacinto. Uma introdução a Pierre Bourdieu. 2010. Revista Cult (Online). https://revistacult.uol.com.br/home/uma-introducao-apierre-bourdieu/ Acesso em: 03/08/2020

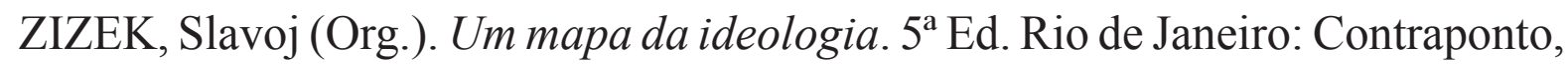
2013 